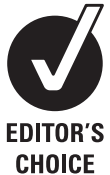

Correspondence to

David DeGrazia, Department of Philosophy, George Washington University, 801 22nd Street, N.W. Room 525, Washington, DC 20052, USA; ddd@gwu.edu

Accepted 15 July 2011

Published Online First

10 November 2011

\title{
Genetic enhancement, post-persons and moral status: a reply to Buchanan
}

\author{
David DeGrazia
}

\section{ABSTRACT}

Responding to several leading ideas from a paper by Allen Buchanan, the present essay explores the implications of genetic enhancement for moral status. Contrary to doubts expressed by Buchanan, I argue that genetic enhancement could lead to the existence of beings so superior to contemporary human beings that we might aptly describe them as post-persons. If such post-persons emerged, how should we understand their moral status in relation to ours? The answer depends in part on which of two general models of moral status-one based on respect and one based on interests -is more adequate. Buchanan tentatively argues that a respect-based model is preferable. I challenge Buchanan's view, along these lines: If we embrace a respect-based model of moral status featuring a threshold that divides persons, who are thought to have full and equal moral status, from sentient nonpersons, thought to have less moral status, then we should acknowledge a second threshold and a level of moral status higher than ours. A better option, I tentatively suggest, is to drop the idea of levels of moral status, accept that all sentient beings have moral status, and allow that some differences in interests and capacities justify some significant differences in how we should treat beings of different kinds.

A being has moral status if she matters, morally, in her own right. Such a being is no mere tool; her interests have moral importance, and not just instrumentally. From another angle, moral agents have moral obligations to-and not merely regarding beings with moral status. Thus understood, this concept makes room both for views that maintain that all who have moral status have it equally and for views that assert differences in moral status among those who have it.

\section{INTRODUCTION}

Persons, uncontroversially, have moral status. Whether fetuses do is notoriously controversial. Increasingly it is claimed that sentient animals have moral status, although many who advance this claim hold views that imply degrees of moral status.

In this paper I will explore the implications of genetic enhancement for moral status. In doing so, I will respond to several leading ideas in an outstanding recent discussion by Allen Buchanan. ${ }^{1}$ By 'enhancement' I will mean the intentional enlarging of human capacities, whether this enlargement occurs by improving existing capacities or by creating new ones.
Genetic enhancement, my futuristic focus, involves the deliberate genetic alteration-with the intention of enlarging capacities-of human gametes (sperm or eggs), embryos, fetuses or postnatal human beings. Capacities to be enlarged may include some that are straightforwardly physical such as endurance and muscularity; cognitive capacities such as memory and the ability to remain focused on a task; and psychological capacities such as dispositions to particular moods and degrees of emotional stability. Cutting across the somewhat artificial distinction between cognitive and psychological capacities are moral capacities such as the ability to be appropriately impartial and the ability to reach defensible moral judgements in conditions of stress.

In exploring the implications of genetic enhancement for moral status, let us begin with three questions.

First, a conceptual question: "Could genetic enhancement in principle lead to the existence of beings so superior to contemporary human beings, in ways that matter to us, that we might aptly describe them as post-persons?" The idea is that their capacities would make them superior in respects that one might plausibly consider relevant to moral status. Buchanan expresses doubt that this idea of a post-person makes sense (p359). ${ }^{1}$ By contrast, I will answer affirmatively and describe such beings.

Second, a factual question: "Is it likely that some day genetic enhancement will produce such beings?" I have no idea, but it doesn't matter for present purposes. How we should think about possible post-persons and their moral status will prove to have implications for how we ought to think about the moral status of presently existing individuals.

Finally, a moral question: "If such post-persons emerged, how should we understand their moral status in relation to ours?" The answer depends in part on which of two models of moral status-one based on respect and one based on interests-is more adequate. Buchanan argues, albeit tentatively, that a respect-based model is preferable because it better accommodates our intuitions regarding the moral status of animals in comparison with ours. 'For many of us', he states, '... it is perfectly plausible to say that humans (or at least those humans who are persons) have a distinct and higher moral status than, say, rats' (p360); accordingly, he refers to 'the commonsense idea that non-human animals have a lower moral status' (p360). ${ }^{1}$ Buchanan further suggests that a respect-based model affords us significant moral protection, no matter what sorts of beings emerge by way of enhancement, 
because it preserves the Moral Equality Assumption: All who have the traits that are sufficient for being a person have equal moral status. Buchanan's suggestion is motivated by his scepticism that the idea of post-persons, defined by way of some threshold that (mere) persons would fail, is promising: '... from the perspective of the respect-based view, it is hard to imagine what a higher threshold-one that required a higher moral status-would be like' (p363). ${ }^{1}$

I will challenge Buchanan's view. Admittedly, one might question the value of challenging a view like Buchanan's that is advanced only tentatively. But the view he suggests grows naturally out of a respect-based account of moral status that many-and perhaps most-contemporary moral theorists would embrace. In challenging Buchanan's view, I will also be challenging the mainstream account of moral status. Moreover, the questions Buchanan has provoked regarding the relationship between human enhancement and moral status are of great independent interest.

The crux of my argument is this: if we embrace a respectbased model of moral status featuring a threshold that divides persons, who are thought to have full and equal moral status, from sentient non-persons, thought to have less (but some) moral status-call this the Respect Model-then we should acknowledge a second threshold and a level of moral status higher than ours. A better option, I suggest (albeit just as tentatively as Buchanan endorses the Respect Model), is to drop the idea of levels of moral status, accept that all sentient beings have moral status, and allow that some differences in interests and capacities justify some significant differences in how we should treat beings of different kinds.

\section{MOTIVATING THE RESPECT MODEL OF MORAL STATUS}

Persons have moral status, so personhood is at least sufficient for moral status. Is it also necessary? Kantian ethics and the contract tradition in moral philosophy suggest as much. Only rational beings, or beings that can be morally accountable to each other, have moral status. However widely held this view may have been over the ages, I suggest that it is not a serious contender today among models of moral status. There are many grounds for rejecting the traditional view, but here I will mention just one: there is no plausible way to account adequately for the wrongness of cruelty to animals without acknowledging the moral status of its victims. It is something about the horse that makes it wrong to abuse her, not merely something about the horse's relationship to certain persons such as the horse's 'owner' or to other persons such as those who care about animals. The horse can suffer and therefore can be harmed in a way that she experiences. So we owe it to the horse not to abuse her. From this it follows that the horse has moral status. Rather than provide a full argument here for the thesis that sentient animals (hereafter simply 'animals') have moral status, I will assume that this thesis has been established for the purposes of this discussion. ${ }^{2}$ At the same time, and importantly for any who may doubt this thesis, the challenges I later direct towards the Respect Model will a fortiori constitute challenges to any view denying that animals have moral status.

On the Respect Model, as defined here, animals have moral status but persons have higher moral status than non-persons. For the sake of simplicity, let us assume that no non-human animal is a person, so that 'person' and 'animal' will be used (slightly inaccurately) as mutually exclusive categories. (One inaccuracy, of course, is the implication that human persons are not animals. More controversially, I claim that at least a few linguistically trained non-human animals have been persons. ${ }^{3}$ )
Thus, on the Respect Model, among the beings with moral status, those whose capacities reach the threshold of personhood have a special moral status. Merging the traditional importance accorded to personhood with the contemporary appreciation of the idea that animals are not mere 'things', the Respect Model can take either of two more specific forms. One specification, a two-tier model, features two planes with all sentient nonpersons having one moral status and all persons having a higher moral status. Another specification, which might be motivated by the idea that sentience itself comes in degrees-just as a light can be off or on but, if on, dimmer or brighter-is a sliding scale model which envisages a continuum of degrees of moral status. A sliding scale of moral status plus a threshold for persons amounts to a sliding scale only for animals; persons, again, are deemed to be special and equal, hence an even plane of moral status for them. Assuming we agree that animals have moral status, should we accept a model in which persons are thought to have higher moral status-that is, any version of the Respect Model?

One way to begin motivating such an approach is to note ways in which persons seem to merit special moral consideration. Consider, for example, the case of Rats versus Children:

In your neighbourhood, rats carry diseases that can be extremely harmful to humans. Several rats have made their way into your house, where you live with your two small children. You try to find a way to remove the rats without harming them or posing great risk to yourself, but come up empty-handed. You decide to kill the rats with the least painful means you can find.

I believe that the decision to kill the rats in this case is morally justified, and that nearly any animal protectionist would agree. Does this judgement imply that persons have higher moral status than animals - or at least some sentient animals, including rats? Not by itself. After all, the rats, however innocently, are invading your house and threatening you and your children.

Consider, therefore, the highly discussed case of Lifeboat:

Four persons and a dog are on a sinking lifeboat. It is obvious that all will drown unless one is tossed overboard. The dog is sacrificed. ${ }^{4}$

In Lifeboat, no one invades anyone's property. And, if the dog seems to pose a threat to the persons just because there isn't room for all five individuals, the same may be said of each person-she equally poses a threat to the other four onboard. Nevertheless, it seems permissible to toss the dog and, indeed, impermissible to toss one of the persons (assuming there are no extraordinary circumstances that might justify tossing one of the persons such as that one of them is trying to murder everyone else or has lapsed into an irreversible coma). Even animal protectionists accept this judgement. Does Lifeboat suggest that persons have higher moral status than other sentient beings?

Not necessarily. Lifeboat involves an unfortunate scenario in which someone with moral status will have to die. Perhaps it indicates some moral priority for persons in situations in which not everyone can be protected, but that does not mean that persons have higher moral status than non-persons. For it is plausible to hold that, in Lifeboat, the persons are threatened by a greater degree of harm than is the dog, having more to lose in dying - an explanation that would justify favouring the persons without implying higher moral status. ${ }^{45}$ (One might argue that if $A$ and $B$ have greatly different capacities to be harmed or greatly different capacities for good in their lives, then their moral statuses differ for that reason. Without denying the possible cogency of this thesis, I simply note its 
contentiousness-supporting my claim that differing capacities to be harmed by death do not straightforwardly entail a difference in moral status.)

What sort of position would entail a truly unambiguous difference in moral status? Buchanan ${ }^{1}$ identifies and endorses such a view, in which animals are appropriately sacrificed on consequentialist grounds whereas persons are regarded as inviolable (pp359-61). This view would justify the more or less routine sacrifice of rats where necessary for the conduct of promising experiments seeking important knowledge. It might also justify animal husbandry that, while avoiding the cruelty of factory farming, routinely harms animals in small ways and kills them for food, even if the food will be consumed by people who have other viable dietary options. This is an attractive view embraced by many morally serious people.

Characterising it further, Buchanan ${ }^{1}$ states:

According to the respect-based account stemming from Kant's moral philosophy, all beings that possess certain capacities have an intrinsic moral worth that in some sense confers inviolability.... Contemporary contractualist moral theorists, broadly considered, ground intrinsic moral worth in the capacity to engage in mutual accountability through the giving and heeding of reasons.

(pp360-1)

Thus, the respect-based view fits most naturally within the deontological tradition stemming from Kant through such contemporary theorists as Scanlon. ${ }^{6}$ When combined with the thesis that animals, too, have moral status-though less than persons - the result is what we have called the Respect Model, a hybrid vision in which animals count morally while only persons have rights in a strong sense of the term that implies inviolability or, more plausibly (permitting some overriding of rights in supreme emergencies), near-inviolability. Importantly, this view incorporates the Moral Equality Assumption-that all persons have equal moral status-protecting persons from the consequentialist spectre of sacrifice in the name of the greater common good. Concretely, it means that an old, cheerless, unproductive person has a right to life no less strong than that possessed by the young, cheerful, productive person. ${ }^{7} 8$

Clearly, the Respect Model, which ascribes special moral status to persons and partial moral status to animals, has several strengths. It protects the Moral Equality Assumption which few would want to abandon; it enjoys the backing of a powerful tradition in moral philosophy and it squares very well with most people's intuitions about appropriate treatment of persons and animals. Nevertheless, the Respect Model faces substantial challenges. In this brief paper, I will discuss just one of them, returning us to the theme of genetic enhancement.

\section{THE SPECTRE OF POST-PERSONS WITH HIGHER MORAL STATUS}

Among present-day terrestrial creatures, we human persons are impressive. We communicate with the explosive power of language. We have strong memories for what we have experienced and learnt, at least in comparison with most animals. We are selfaware to a high degree. Further, even if many animals display a sort of instrumental rationality, persons are rational to a higher degree and probably in unique ways. Moreover, we possess the capacities that together constitute moral agency. In the contractarian tradition, moral agency is of overriding importance because it permits an individual to be accountable to other individuals.

These and other characteristically human traits furnish the material for our concept of a person. On the Respect Model, therefore, they provide the basis for special moral status, justi- fying the claim that beings with these capacities are virtually inviolable, whereas animals may be used as resources so long as such use has a sufficiently good benefit/cost ratio and is appropriately humane.

Yet any honest examination of persons, at least as we know them today, must acknowledge certain limitations. These can be seen by way of contrast with post-persons, a type of being that could in principle result from the accumulation of several successes in genetic enhancement. Let me introduce them with a case:

A Future with Post-persons. It is 2145 . Out of massive human population, a discrete population has evolved, through carefully planned genetic modifications, and has achieved a considerable number. These beings are in many respects superior to unenhanced people. They typically learn 10-12 human languages, a feat made possible by their retention throughout their lifetimes of the spongelike capacity that young human children have always had. Their memories, on average, are as capacious as those considered prodigious among the unenhanced population. They have far more extensive self-awareness than ordinary persons, being able to detect with little or no effort the ways in which their biological endowment, early environment (which they remember very clearly) and present environment create myriad dispositions and pressures to think and behave in particular ways. Being far more rational than ordinary people, they are embarrassed to have evolved from a type of creature so susceptible to superstitions, myths, cultural prejudices, ethnic and religious discrimination, unconscious bias in favour of one's own interests, a litany of logical fallacies and so on. They marvel at the way even the philosophers and scientists among the unenhanced population regularly deceive themselves about their own strengths and weaknesses, their motives and the likelihood of adhering to resolutions. Bringing together several of these strengths, the post-persons are vastly superior in their moral capacities. First, they are consistently impartial whenever impartiality is morally required. Second, because they screen out distracting stimuli and think very quickly, they reach correct moral judgements in conditions of stress no less consistently than they do in leisurely reflection. Third, they suffer from weakness of will so seldom that any of their members who does so is regarded as having a psychological disorder. Finally, in comparison with ordinary persons, these enhanced humans are enormously adept at envisaging the likely consequences of their choices and identifying the implications of their moral judgements.

In A Future with Post-persons, we encounter beings who are much more intelligent, reasonable and morally reliable than ordinary persons. The differences between ordinary persons and postpersons are so great (let's now add to the case) that post-persons tend to regard themselves as different in kind from persons. Just as persons tend to say (with some exaggeration) that they are rational while animals are irrational, post-persons tend to say that they are appropriately impartial whereas persons are not. Just as persons tend to regard themselves as agents who plan, in contrast to animals who can barely perceive the future, post-persons regard themselves as far-sighted and accurate in perceiving the future and as deciding wisely on that basis, in contrast to persons who are poor prognosticators and worse decision-makers. Just as persons tend to think of themselves as moral agents who can be held accountable to one another and of animals as simply not making this grade, post-persons regard themselves as reliable moral agents in contrast to the unenhanced haphazard moral agents. While post-persons do not have the disdain for persons that persons so frequently have had for animals, considering such disdain just one more form of group prejudice, post-persons are keenly aware of the many differences separating the two populations. Indeed, again, they tend to perceive a difference in kind. 
In 2145 , a debate breaks out among post-persons. The question on which they are divided is whether their superiority to unenhanced persons entails a difference in moral status. Do post-persons alone enjoy near- inviolability? Those who think so believe that persons have deceived themselves in conferring this full moral status on themselves. "The usual narcissism and lack of imagination", comment some post-persons. According to these post-persons, ordinary persons have moral status but may be sacrificed on consequentialist grounds, and not only in extreme circumstances such as those featured in the trolley problem. $^{9}$

Some who hold this view argue for a distinction in moral status between persons and other animals. They hold that persons must be given equal consideration to post-persons in consequentialist reasoning-meaning persons can be sacrificed only when doing so would maximise utility, impartially considered-whereas other animals can be given somewhat less consideration; in contrast, post-persons cannot be sacrificed on grounds of utility except in highly unusual, extreme circumstances that have been carefully catalogued. (Post-persons are so impartial that they agree they should be sacrificed if, say, their corpulent bodies are blocking the only exit from a cave in which the water level is quickly rising. Not only do they agree in principle; they agree in the actual circumstances in which they will be sacrificed.) Others who hold that post-persons have higher moral status than persons believe that persons and animals have the same moral status. Basically, they argue, there are two levels among beings with moral status: reliable moral agents and sentient beings of lesser capacities.

Another group of post-persons, however, rejects the hierarchy of moral status dividing persons and post-persons. Some among this group hold that the trait conferring full moral status is personhood. On their view, although post-persons are fortunate not to be mere persons, the latter are not tools for post-personal use. Others among those who reject the proposed hierarchy go further in their egalitarianism, denying the traditional idea that personhood confers special moral status. On their view, all sentient beings, having interests and experiential welfare, count morally and no further characteristic justifies the idea that some count more than others. Somewhat unfashionably and with all sorts of qualifications, they cite Bentham and Singer as ancient sources of wisdom.

Who has the more justified position in this debate? Do postpersons have higher moral status than persons? Are persons today deluded in thinking that they will continue to be recognised as enjoying the highest moral status no matter what sorts of beings emerge through genetic enhancement? Are those persons who embrace the Respect Model wrong to think persons have higher moral status than animals?

I am unsure how to answer these questions. I'm prepared, though, to stand by this comparative claim: post-persons have about as much justification in believing that they have higher moral status than persons as persons have in believing that they have higher moral status than animals. Am I too quick to endorse this comparison? Buchanan ${ }^{1}$ suggested (in correspondence; see also pp360-1) that those who embrace the Respect Model and emphasise mutual accountability as the basis for moral status are likely to contend that the capacity to be accountable makes all the difference here-that is, both persons and post-persons can be accountable, sentient non-persons such as dogs cannot-and these facts justify special and equal moral status for all who can be accountable.

Yet this argument seems to me open to an obvious rejoinder: for post-persons, it will seem natural to think that unenhanced haphazard moral agents cannot be relied upon to reach accurate moral judgements, and for this reason are far less accountable for their behaviour than reliable moral agents are. "But 'far less accountable'," one may object, "is still accountable. Persons are within the class of those who are accountable, which justifies the claim of full and equal moral status." But consider this: some animals and humans who are not moral agents are nevertheless a little bit accountable for their behaviour-or accountable for a little bit of their behaviour. A well-trained dog, for example, can be expected to come when called, not to urinate in the house if walked frequently enough, not to bite friends of the family, and so on. A young child who is too immature to be regarded as a moral agent for most purposes can still be expected not to hit other children. After all, the capacities that constitute moral agency come in degrees. Draw the line (in any reasonable place) for how much of these capacities is enough to make one a moral agent, and there will be some beings who don't make the grade yet are slightly accountable. On the Respect Model, therefore, one must judge that the vast inferiority of dogs' accountability justifies their having a lesser moral status. Mutatis mutandis, post-persons may reason that the vast inferiority of haphazard moral agents, in comparison with reliable moral agents, justifies their having lower moral status. In effect, a great enough difference in degree amounts to a difference in morally relevant kind.

Thus, any acceptance of the Respect Model should be only partial: the hierarchy dividing persons and animals can survive, but the claim that persons have full moral status should be replaced with the claim that "persons have equal moral status relative to each other, but less moral status than post-persons have'. Hence, there are three levels (or perhaps two levels and, for animals, a sliding scale) of moral status among beings who have it. A more radical departure from the Moral Equality Assumption, which could be motivated by the fact that most personhood-relevant traits admit of degrees, ${ }^{10}$ would probably be too unpalatable to consider: a sliding scale for sentient nonpersons; another sliding scale, starting at a higher level, among persons; and an even plane for post-persons.

For obvious reasons, we dislike the idea that we may have less than full moral status and we are likely to reject it. But this idea may be correct; after all, we unenhanced persons are highly subject to self-interested prejudice in our moral reasoning. It is not crystal clear to me that it would be wrong of post-persons to regard us partially as resources for their use, just as the Respect Model views animals as partially resources for our use. On the other hand, it is also not obvious to me that this hierarchical view would be correct. Maybe post-persons, though vastly superior in certain important ways, have no greater moral status than we do. Most of us will like this idea. But, presumably, it comes at the price of levelling out moral status between persons and other sentient beings. For there is nothing magical about personhood that confers special and unsurpassable moral status in view of the fact that we are such haphazard moral agents in comparison with post-persons.

If, as I am tentatively inclined to believe, we should do away with the idea of levels of moral status, how should we understand our moral status in relation to that of animals and post-persons?

\section{REMARKS ABOUT AN ALTERNATIVE: THE INTERESTS MODEL}

According to the Interests Model, all sentient beings have interests and an experiential welfare, possession of which is the sole basis for moral status. The advantages of this approach include the following: (1) it straightforwardly explains the 
wrongness of cruelty to animals; (2) it avoids any credible charge of resting on intuitions distorted by self-serving bias; (3) it generates no problem of non-paradigm humans (the problem that the Respect Model apparently implies that human nonpersons have inferior moral status); and (4) it does not imply that persons have lower moral status than post-persons. The traditional view according to which animals entirely lack moral status shares none of these four advantages. The Respect Model, by contrast, shares the first advantage insofar as it attributes some moral status to animals, but it cannot claim any of the other three advantages. The great challenge facing the Interests Model, meanwhile, is to make sense of some morally important differences between persons and animals.

Return to the cases of Rats versus Children and Lifeboat. The judgements that we should favour the children and the people on the lifeboat are persistent, strong and shared even by animal protectionists; these judgements ought to be accommodated. So should many others that give priority in certain instances to persons when their interests compete with those of animals. But, as we saw in the two cases, at least sometimes the judgements can be explained without appeal to differences in moral status. In Rats versus Children, the rats are invading one's home and posing a threat, explaining the permissibility of killing them as a last resort. In Lifeboat, the dog-who will die anyway if no one is sacrificed-will suffer a lesser harm in losing her life than one of the persons would suffer in dying. The question is whether appeals to factors other than differences in moral status will adequately explain the differences in how we ought to treat persons and animals. Supporters of the Interests Model defend, or at least assume, an affirmative answer to this question. Despite being inclined to agree, I consider the issue to be wide open.

Let me mention, in closing, another morally important difference between persons and animals that any adequate ethical theory will have to accommodate. This is the difference between those beings to whom a principle of respect for autonomy applies and those beings to whom this principle does not apply, although at least consequentialist principles such as non-maleficence apply to them. Paternalism is a serious moral issue where respect for autonomy conflicts with one or more consequentialist principles. It is not a serious issue when I prevent my young daughter from drinking alcohol, for her own good, or when I drag my dog to the vet, for his own good.
Having a developed capacity for autonomous decision-making is a morally important difference separating those for whom paternalism is a serious issue from those for whom it is not. But this point need not indicate a difference in moral status, say, between persons and dogs any more than it indicates a difference in moral status between competent adults and young children. This is just one example of a morally significant difference that does not amount to a difference in moral status. If the Interests Model of moral status is correct, then no morally important difference between persons and animals-or between post-persons and persons-amounts to a difference in moral status. On this view, there are no levels of moral status among those who have it; rather, differences in interests, capacities and circumstances justify certain differences in morally appropriate treatment. But the justified differences in treatment with regard to persons and animals are less extensive than moral tradition and standard practice have supposed. We should harm animals far less than we currently do-and we should stop regarding them primarily as resources for our benefit.

Acknowledgements A draft of this paper was presented on 12 June 2010 at the University of London. I would like to thank attendees-especially John Harris, Sarah Chan and Muireann Quigley-for their feedback. I also thank Allen Buchanan and two anonymous reviewers for their feedback.

Competing interests None.

Provenance and peer review Commissioned; internally peer reviewed.

\section{REFERENCES}

1. Buchanan A. Moral status and human enhancement. Philos Publ Aff 2009:37:346-81.

2. DeGrazia D. Taking Animals Seriously: Mental Life and Moral Status. Cambridge: Cambridge University Press, 1996. Chapter 3.

3. DeGrazia D. On the question of personhood beyond Homo sapiens. In: Singer P, ed In Defense of Animals. Oxford: Blackwell, 2003:40-53.

4. Regan T. The Case for Animal Rights. Berkeley: University of California Press, 1983:351-3.

5. DeGrazia D. The harm of death, time-relative interests, and abortion. Philos Forum 2007:38:57-80.

6. Scanlon TM. What We Owe to Each Other. Cambridge, MA: Harvard University Press, 1998.

7. McMahan J. The Ethics of Killing. New York: Oxford University Press, 2002.

8. Warren MA. Moral Status. Oxford: Oxford University Press, 1997.

9. Thomson JJ. Killing, letting die, and the trolley problem. Monist 1976;59:204-17.

10. DeGrazia D. Great apes, dolphins, and the concept of personhood. South J Philos 1997;35:301-20. 